\title{
Pharmacologic effects of Cl-581, a new dissociative anesthetic, in man
}

\author{
Pharmacologic actions of CI-581, a chemical derivative of phencyclidine, were \\ determined in 20 volunteers from a prison population. The results indicate that this drug is \\ an effective analgesic and anesthetic agent in doses of 1.0 to $2.0 \mathrm{mg}$. per kilogram. With \\ intravenous administration the onset of action is within 1 minute and the effects last for about \\ 5 to 10 minutes, depending on dosage level and individual variation. No tachyphylaxis was \\ evident on repeat doses. Respiratory depression was slight and transient. Hypertension, \\ tachycardia, and psychic changes are undesirable characteristics of the drug. Whether these \\ can be modified by preanesthetic medication was not determined in this study. Recovery \\ from analgesia and coma usually took place within 10 minutes, although from \\ electroencephalographic evidence it may be assumed that subjects were not completely \\ normal until after 1 to 2 hours. No evidence of liver or kidney toxicity was obtained. \\ CI-581 produces pharmacologic effects similar to those reported for phencyclidine, but \\ of shorter duration. The drug deserves further pharmacologic and clinical trials. It is \\ proposed that the words "dissociative anesthetic" be used to describe the mental state \\ produced by this drug.
}

\author{
Edward F. Domino, M.D., Peter Chodoff, M.D., and Guenter Corssen, M.D. \\ Ann Arbor, Mich. \\ Departments of Pharmacology and Anesthesiology, The University of Michigan Medical Center
}

The remarkable analgesic and anesthetic properties of phencyclidine have stimulated a search for derivatives that would offer the same benefits with less psychotomimetic effects. ${ }^{3}$ Recent studies in laboratory animals by McCarthy and co-workers ${ }^{7}$ indicate that such an agent might be found in CI-581, a chemical derivative of phencycli-

Supported in part by a grant from the Parke, Davis Company and by MY-02653-07 of the U. S. Public Health Service.

Received for publication Jan. 4, 1965. dine, with the formula, 2-(o-chlorophenyl)2-methylamino cyclohexanone $\mathrm{HCl}$ (Fig. 1). CI-581 produced immobilization and/or general anesthesia in a variety of animals and in a broad range of dosages. Although this compound is less potent on a milligram per kilogram basis than phencyclidine, its central depressant action is significant with much less central excitatory effects. Moreover, CI-581 has a shorter duration of action which should allow greater controlability in clinical use. 


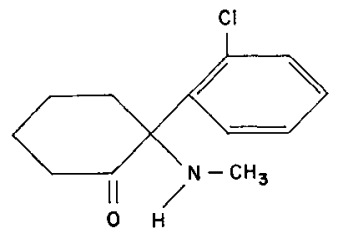

$c /-58 l$

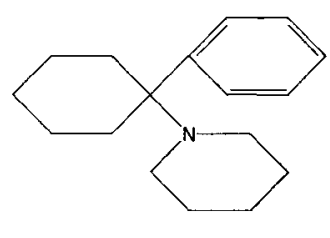

PHENCYCLIOINE
Fig. 1. Chemical structures of CI-581 and phencyclidine.

For these reasons a study was undertaken to determine the pharmacodynamic effects of CI-581 in human subjects. This article describes the results of this initial phase I investigation.

\section{Methods}

Male inmates of a prison volunteered as subjects. From this group, 20 were selected ranging from 25 to 48 years old, with a mean age of 37.4. Preliminary examinations ruled out any physical and mental aberrations. During the week before the experiment, and also one day and one week afterward, the following laboratory studies were carried out in all cases: hemoglobin and hematocrit determinations, erythrocyte and leukocyte counts, sedimentation rate, platelets, SGOT, SGPT, alkaline phosphatase, blood urea nitrogen, sodium, potassium, chloride, and glucose (Table I). Routine urinalyses were also performed; these included color, appearance, specific gravity, albumin, sugar, $\mathrm{pH}$, ketones, bile, red and white cell counts for both high- and lowpower field, and presence of casts.

All subjects fasted at least 12 hours before the experimental drug was administered. At the beginning of the experiment, the subject was placed supine and connected to a polygraph for measuring vital signs. EEG recordings were made from $\mathrm{F}_{3}$, $\mathrm{C}_{3}, \mathrm{P}_{3}$, and $\mathrm{O}_{1}$ to both ears as reference (10-20 system $^{6}$ ); EKG was recorded from lead II, and respiration monitored by thoracic and abdominal rubber cuffs, or a Fleisch pneumotachograph which gave an accurate measure of respiratory rate and also tidal volume changes measured as the area under the curve with a Gelman planimeter. Arterial blood pressure was monitored by the inflatable cuff method or intra-arterial recordings by a Statham pressure transducer. In addition, arterial $\mathrm{pO}_{2}$ and venous blood sugar determinations were made.

The drug, CI-581, was administered intravenously into the tubing of a saline infusion over a one minute period, in doses ranging from 0.1 to $2.0 \mathrm{mg}$. per kilogram body weight. Each subject received the drug on two different days, with an interval of at least a week. The effects of CI-581

Table I. Means and ranges of laboratory data before and after CI-581 given to 18 subjects

\begin{tabular}{|c|c|c|c|c|c|c|}
\hline & Hemoglobin & Hematocrit & $R B C$ 's & WBC's & ESR & Platelets \\
\hline \multicolumn{7}{|c|}{ Pretreatment } \\
\hline Mean & 14.6 & 44 & 5.11 & 8.0 & 6 & 280 \\
\hline Range & $13.1-15.5$ & $41-46$ & $4.54-5.51$ & $5.0-11.8$ & $1-9$ & $200-417$ \\
\hline \multicolumn{7}{|c|}{ Posttreatment (24 to 72 hours) } \\
\hline Mean & 15.3 & 47 & 5.30 & 9.1 & 6 & 239 \\
\hline Range & $14.1-16.8$ & $43-51$ & $4.92-5.76$ & $5.5-13.3$ & $1-10$ & $215-280$ \\
\hline \multicolumn{7}{|c|}{ Posttreatment (day 7) } \\
\hline Mean & 14.8 & 45 & 5.21 & 9.1 & 7 & \\
\hline Range & $13.8-15.7$ & $41-48$ & $4.82-5.55$ & $5.5-15.1$ & $2-16$ & \\
\hline \multicolumn{7}{|c|}{ After second treatment ( 7 days) } \\
\hline Mean & 14.8 & 45 & 5.18 & 8.6 & 7 & \\
\hline Range & $12.7-16.6$ & $40-50$ & $4.39-5.89$ & $4.6-12.7$ & $1-13$ & \\
\hline
\end{tabular}


on somesthetic and visual input into the cerebral cortex were studied by means of computer techniques described previously, ${ }^{2-5}$ and the data were analyzed according to Snedecor. ${ }^{8}$

\section{Results}

Analgesic and anesthetic effects. The effect of CI-581 on pain sensation was tested by crushing the skin over the subject's chest or arms with a hemostat. Loss of consciousness was gauged by constant quizzing of the subject, and the end point of coma was taken as the time the subject could reestablish verbal communication with the investigators, even though his responses were far from normal at this time.

Fig. 2 illustrates the effects of increasing doses of CI-581 on duration of coma, the scatter of points indicating the variability. At doses of $0.1 \mathrm{mg}$. per kilogram, no significant alteration in level of consciousness was noted, and at $0.5 \mathrm{mg}$. per kilogram only half the subjects showed loss of consciousness. In doses of $1.0 \mathrm{mg}$. per kilogram, the duration of coma ranged from 3 to $10 \mathrm{~min}$ utes, with a mean of 5.7 . With $1.5 \mathrm{mg}$. per kilogram the mean duration was 9.1 minutes and at $2.0 \mathrm{mg}$. per kilogram it was 10 minutes.

The syndrome immediately following the administration of the drug was of interest.

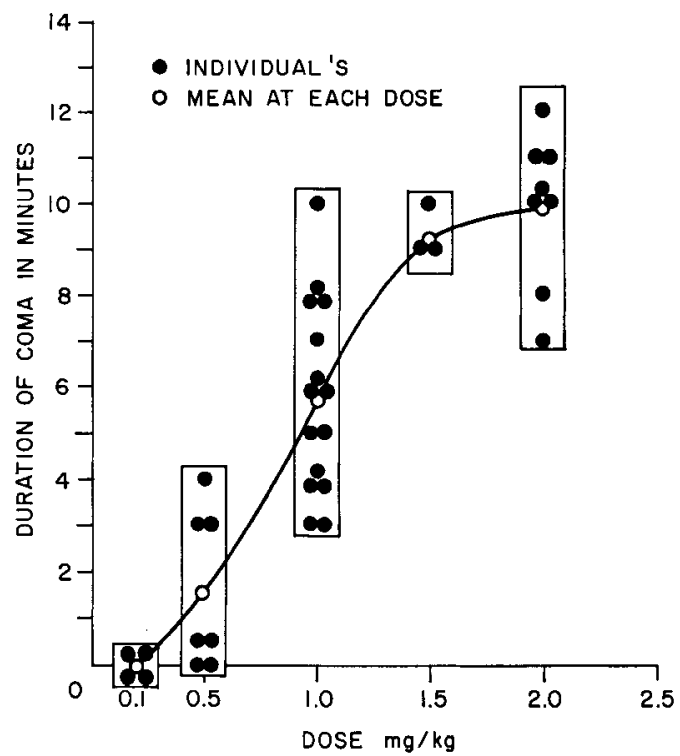

Fig. 2. Effects of increasing doses of CI-581 on duration of coma.

Usually the subject was asked to keep his eyes closed during the procedure. Within a minute after drug injection, the subject reported numbness of the entire body, although sensation to touch remained intact. After $1.0 \mathrm{mg}$. per kilogram or more of CI581 , the subject would open his eyes and at the same time lose contact with the environment. Both corneal and wink reflexes were brisk at this time, and marked nystag-

\begin{tabular}{|c|c|c|c|c|c|c|c|c|c|}
\hline SGOT & SGPT & $\begin{array}{c}\text { Alkaline } \\
\text { phosphatase }\end{array}$ & $\begin{array}{c}\text { Thymol } \\
\text { turbidity }\end{array}$ & $B U N$ & Bile & $\mathrm{Na}$ & $K$ & $\mathrm{Cl}$ & $B S P$ \\
\hline $\begin{array}{l}14 \\
8-25\end{array}$ & $\begin{array}{l}12 \\
5-34\end{array}$ & $\begin{array}{l}7.8 \\
5.0-10.3\end{array}$ & $\begin{array}{l}2.8 \\
0.5-6.8\end{array}$ & $\begin{array}{l}14 \\
9-17\end{array}$ & $\begin{array}{l}0.4 \\
0.3-0.7\end{array}$ & $\begin{array}{l}145 \\
140-148\end{array}$ & $\begin{array}{l}4.6 \\
4.1-5.2\end{array}$ & $\begin{array}{l}109 \\
106-112\end{array}$ & $\begin{array}{l}4 \\
2-9\end{array}$ \\
\hline $\begin{array}{l}16 \\
8-28\end{array}$ & $\begin{array}{l}14 \\
5-38\end{array}$ & $\begin{array}{l}8.8 \\
5.4-13.7\end{array}$ & $\begin{array}{l}3.1 \\
0.3-8.8\end{array}$ & $\begin{array}{l}13 \\
9-20\end{array}$ & $\begin{array}{l}0.4 \\
0.1-0.6\end{array}$ & $\begin{array}{l}146 \\
143-149\end{array}$ & $\begin{array}{l}5.0 \\
4.2-5.7\end{array}$ & $\begin{array}{l}107 \\
100-112\end{array}$ & \\
\hline $\begin{array}{l}16 \\
10-33\end{array}$ & $\begin{array}{l}13 \\
4-39\end{array}$ & $\begin{array}{l}8.9 \\
5.2-13.9\end{array}$ & $\begin{array}{l}2.8 \\
0.5-6.9\end{array}$ & $\begin{array}{l}13 \\
8-20\end{array}$ & $\begin{array}{l}0.4 \\
0.1-1.0\end{array}$ & $\begin{array}{l}144 \\
141-148\end{array}$ & $\begin{array}{l}4.8 \\
4.1-5.6\end{array}$ & $\begin{array}{l}107 \\
100-114\end{array}$ & \\
\hline $\begin{array}{l}18 \\
11-45\end{array}$ & $\begin{array}{l}15 \\
5-53\end{array}$ & $\begin{array}{l}9.0 \\
5.9-13.2\end{array}$ & $\begin{array}{l}3.3 \\
1.1-9.7\end{array}$ & $\begin{array}{l}13 \\
8-22\end{array}$ & $\begin{array}{l}0.4 \\
0.2-0.7\end{array}$ & $\begin{array}{l}146 \\
141-149\end{array}$ & $\begin{array}{l}4.8 \\
4.2-5.4\end{array}$ & $\begin{array}{l}107 \\
101-112\end{array}$ & $\begin{array}{l}5 \\
3-9\end{array}$ \\
\hline
\end{tabular}


mus was noted. Complete analgesia was evidenced by the lack of reaction to various pain-inducing procedures. Many subjects showed marked lacrimation and profuse sweating. The patellar, Achilles, and " $\mathrm{H}$ " reflexes were hyperactive. During the initial phase of coma, respiration was slightly depressed, although respiratory assistance was not needed. In some instances, however, manual support of the chin was required to maintain a patent airway. Some subjects clenched their jaws tightly, as if holding something in their teeth. Skeletal muscle tone appeared to be increased in the neck and extremities; tendon reflexes were hyperactive. Closing the eyes usually heralded return to consciousness, and shortly thereafter the subject responded to questions. Difficulty in speaking, as well as evidence of analgesia, continued for a few minutes after verbal contact was re-established.

During the recovery period the subjects showed considerable variability in psychic reaction. Some were completely oriented in time and place and showed no significant changes. Others showed marked alteration in mood and affect, some becoming apprehensive and aggressive and others markedly withdrawn. Almost all the subjects felt entirely numb, and in extreme instances stated that they had no arms or legs, or that they were dead. If they were touched, however, or moved, such stimuli were perceived. Neurologically all subjects showed rotatory nystagmus and ataxia. Diminution of visual acuity was marked. Other reactions noted included feelings of estrangement or isolation, negativism, hostility, apathy, drowsiness, inebriation, hypnogenic states, and repetitive motor behavior.

At times some of the subjects had vivid dreamlike experiences or frank hallucinations. Some of these involved the recall of television programs or motion pictures seen a few days before, or they were at home with their relatives, or were in outer space, and so on. Some of these phenomena were so real that the subjects could not be certain they had not actually occurred.

Usually these psychological aberrations subsided completely within a half hour after awakening. The subjects gradually became well oriented and frequently expressed amazement at the experience; most found the experience pleasant and were willing to undergo a second experiment, although 2 refused to continue. Usually the subjects appeared completely normal within 1 to 2 hours, playing cards or pool, or otherwise engaging in the activities around them.

It was of interest to determine whether immediate repetition of another dose of CI-581 would produce anesthesia and analgesia. Accordingly, 10 subjects who had been given an initial dose of $1 \mathrm{mg}$. per kilogram were given the same dose a second time immediately after the initial coma had ended. In this series the coma had lasted 3 to 8 minutes, with a mean duration of 6 . After the second dose, the periods of coma ranged from 5 to $12 \mathrm{~min}$ utes, with a mean duration of 8 (Fig. 3 ). It was concluded that repeated doses of CI-581 cause a slight increase in the duration of coma. No evidence of tolerance was noted under these conditions.

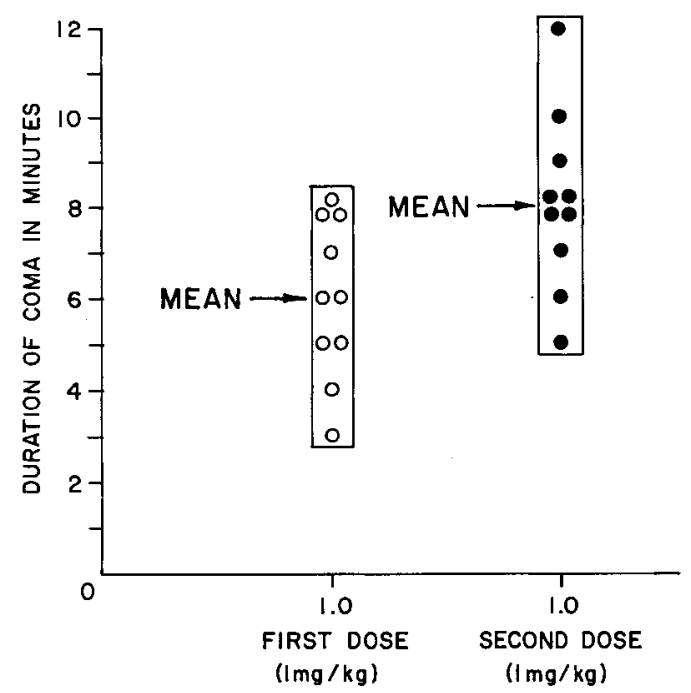

Fig. 3. Effects of a repeated dose of CI-581 on mean duration of coma. 
The most dramatic finding in this aspect of the study was the marked degree of analgesia without coma which could be induced by CI-581. This was demonstrated dramatically when the drug was given as a continuous intravenous infusion, accomplished by administering a total of $100 \mathrm{mg}$. of CI-581 in $100 \mathrm{ml}$. of saline. At approximately 125 to 180 drops per minute, the subject showed profound analgesia without loss of consciousness for about $10 \mathrm{~min}$ utes. During this period he responded to questions though speech was slurred. Although the subject was conscious, he felt absolutely no pain to severe pinching with a hemostat.

Cardiovascular effects. CI-581 produced increases in arterial blood pressure in human subjects, as it did in earlier studies involving dogs and monkeys. ${ }^{7}$ The cardiovascular changes were observed at dosage levels which were not necessarily associated with coma. Fig. 4 illustrates the effects of increasing doses of CI-581 in terms of mean change over the control level in blood pressure and heart rate. Also shown are the effects of saline injection given to the subject as though it were active drug; slight increases in heart rate and blood pressure were noted under these conditions. Although doses of $0.1 \mathrm{mg}$. per kilogram did not produce coma, they did cause blood pressure increases of about $25 \mathrm{~mm}$. $\mathrm{Hg}$ systolic and $16 \mathrm{~mm}$. $\mathrm{Hg}$ diastolic, as well as a slight increase in heart rate. The mean blood pressure values increased with larger doses of CI-581; in heart rate, however, the greatest increase was noted at doses of $0.5 \mathrm{mg}$. per kilogram of CI-581; larger doses did not induce any further change. The elevated diastolic pressures probably indicated increased peripheral resistance.

Fig. 5 shows the mean per cent increase over control levels of systolic and diastolic blood pressures at various dosage levels. These data are similar to those in Fig. 4. The maximum increases were noted within 5 minutes after drug administration. The return to preinjection levels did not coincide with recovery from coma. About 10 to 20 minutes after partial recovery, at a time when the subject clearly was in contact with the environment, the arterial blood pressure was still slightly elevated over control levels, and it did not return to normal until after about one hour.

The effects of a second dose of CI-581 were observed in 10 subjects. A few minutes after the initial dose of $1 \mathrm{mg}$. per kilogram of CI-581, increases in both systolic and diastolic blood pressures were noted, as illustrated in the control bar graph in Fig. 6. When contact was reestablished for each subject, about 10 minutes after drug administration, the blood pressures were still somewhat elevated. A second dose of

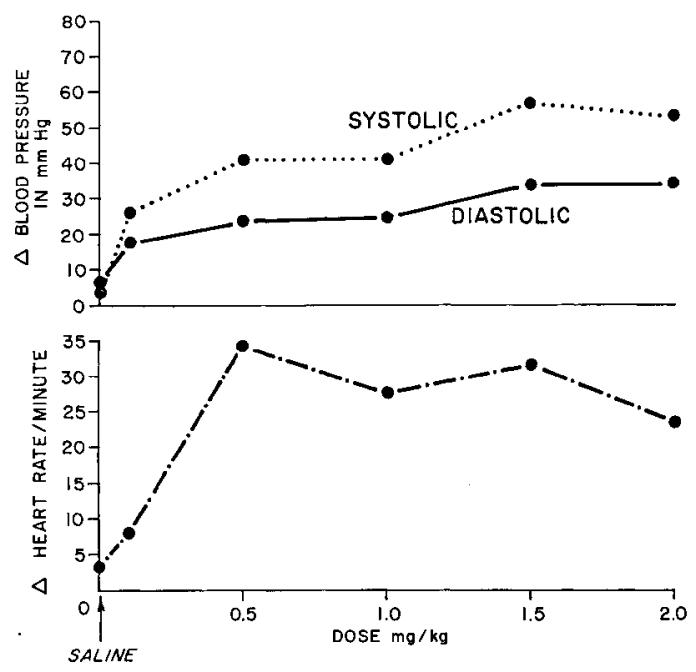

Fig. 4. Effects of increasing doses of CI-581 on mean change in blood pressure and heart rate in 20 subjects.

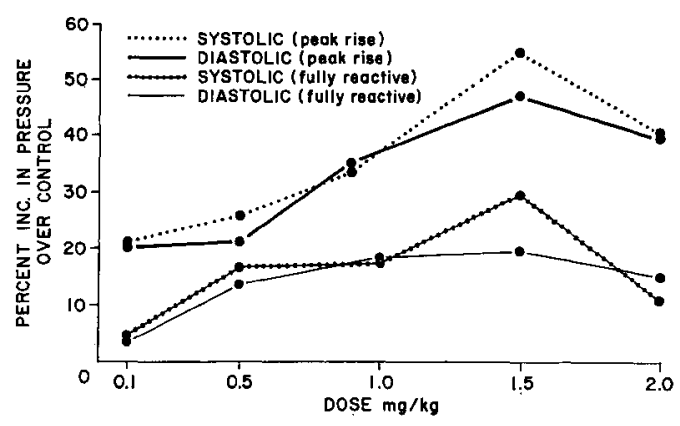

Fig. 5. Effects of increasing doses of CI-581 on peak blood pressure during anesthesia and recovery. 


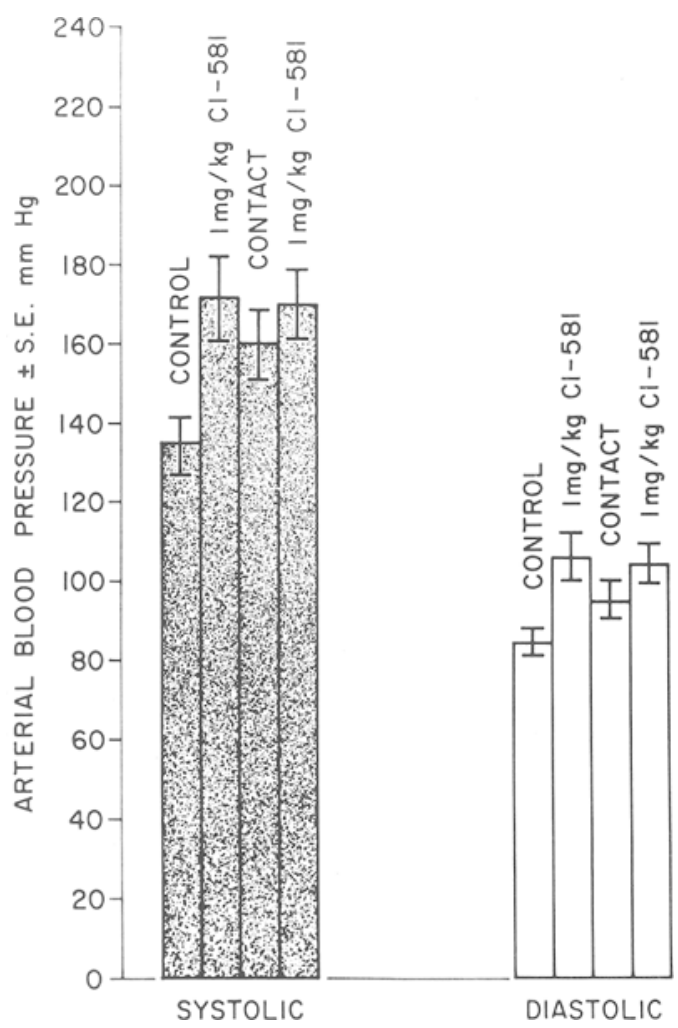

Fig. 6. Effects of a repeat dose of CI-581 on mean arterial blood pressure.

$1 \mathrm{mg}$. per kilogram of CI-581 given at this time again produced anesthesia and increased blood pressure, which reached about the same levels as noted during the peak action of the first dose.

Respiratory effects. In anesthetic doses, CI-581 produced transient respiratory depression. Most of the subjects did not need assistance in maintaining a patent airway. Several objective measures of vital signs were obtained, as indicated in Fig. 7. The simplest of these included the recording of thoracic and abdominal respiration by means of rubber cuffs connected to suitable strain gauges and the polygraph. Frequently both the thoracic and the abdominal ventilation was altered, but it was obvious that respiratory rate was much less affected than tidal volume. As can be seen, respiratory rate was maximally depressed, 1 or 2 minutes after drug injection, from mean rates of about 18 to about 10 . Return to preinjection values took place gradually over the next 3 to 5 minutes. To rule out possible mechanical obstruction, intubation was carried out in 2 subjects following intratracheal instillation of $5 \mathrm{ml}$. of 2 per cent lidocaine. The endotracheal tube was attached to a Fleisch pneumotachograph. A transient but often marked decrease in ventilation was observed 1 or 2 minutes after drug injection, the tidal volume decreasing more than the rate. Similar findings were noted in 4 other subjects who breathed through the Fleisch pneumotachograph without intubation.

As another index of respiratory function, the Waters ear oximeter was used for a polygraph record of the relative per cent arterial oxygen saturation. Since ear oximetry yields qualitative rather than quantitative values, the arterial $\mathrm{pO}_{2}$ also was determined in 2 subjects by means of an arterial catheter placed, under local anesthesia, in the brachial artery at the level of the antecubital fossa.

All of these vital signs were recorded before and after the administration of two doses of CI-581, $1 \mathrm{mg}$. per kilogram each, given 5 minutes apart. Fig. 8 shows the changes following the administration of the drug in one subject. The first injection pro-

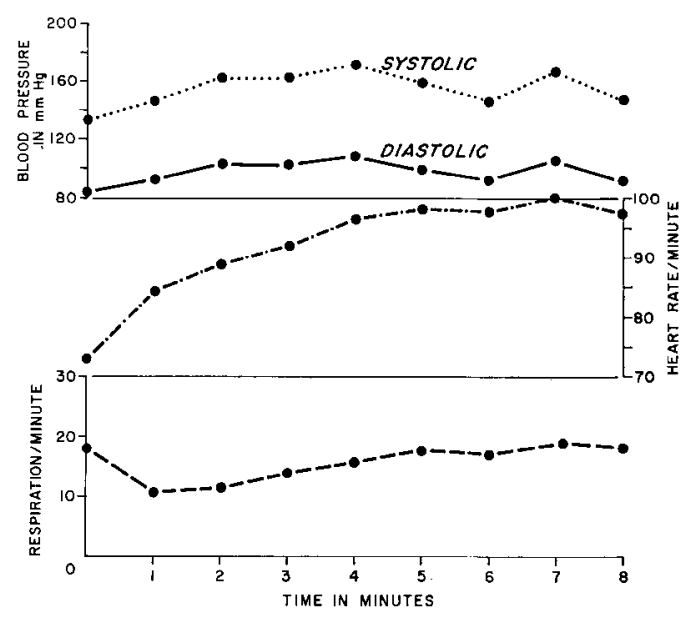

Fig. 7. Effects of $1 \mathrm{mg}$. per kilogram of CI-581 on mean arterial blood pressure, heart rate, and respiration. 


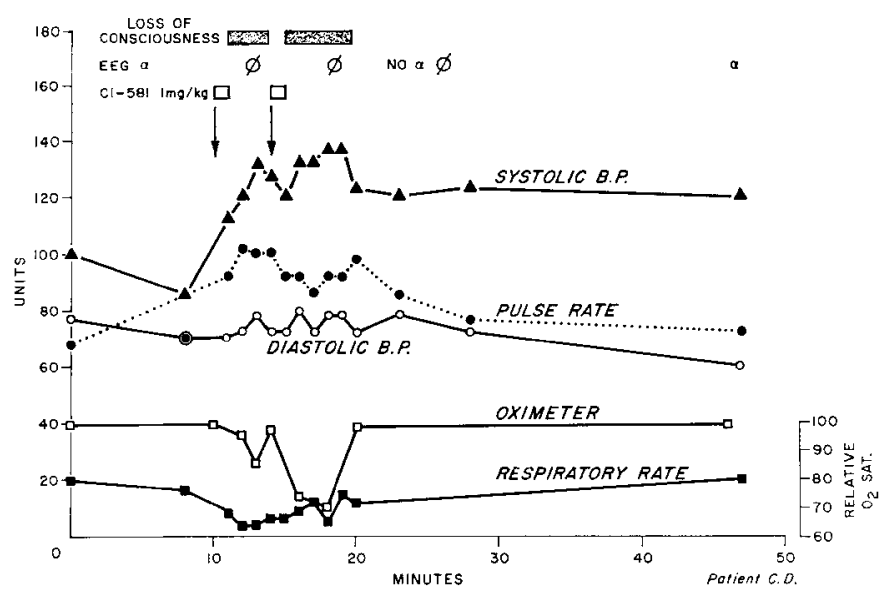

Fig. 8. Effects of CI-581 anesthesia on vital signs in a subject.

duced increases in systolic and diastolic pressures and decreases in respiratory rate and arterial oxygen saturation with the values returning gradually to control levels. The effects of the second injection were similar to those of the first.

Electroencephalographic effects. Doses of 0.5 to $2.0 \mathrm{mg}$. per kilogram of CI-581 given intravenously produced consistent and marked changes in the EEG in all subjects. During saline infusion, with the subject resting comfortably and his eyes closed, alpha rhythm was recorded in the parietal and occipital areas in most instances. From the tracing in upper left-hand panel of Fig. 9 , it can be seen that alpha discharge was recorded predominantly in $\mathrm{O}_{1}$ to both ears as reference. Alphalike waves were also recorded from $\mathrm{P}_{3}, \mathrm{C}_{3}$, and to a lesser extent from $F_{3}$. Characteristic thetalike waves were recorded at dosage levels which produced coma; these were distributed over most of the cerebral hemisphere. Typical thetalike rhythm is shown in upper righthand panel of Fig. 9, 6 minutes after the administration of $1.5 \mathrm{mg}$. per kilogram of CI-581, when the subject was unresponsive. It can be seen that this activity was present in all leads but most prominently in $P_{3}$. About 10 minutes after drug injection, the subject regained consciousness and the theta rhythm was replaced by typical lowvoltage, fast frequency activity. Complete analgesia was still present although the subject was awake and communicating with the investigators. After analgesia disappeared and the subject was in full contact with his environment, there still were no alpha waves. This rhythm was not reestablished until at least a half to one hour after drug injection. The lower right-hand panel in Fig. 9 shows the partial return of alpha rhythm 42 minutes following drug injection.

The abolishing of the alpha waves and induction of theta activity were the most consistent and typical EEG effects of CI581. During the period of coma as well as the recovery phase of some patients, increased skeletal muscle activity was recorded, which correlated with the marked increase in tone often noted in the masseter and temporal muscles. Delta activity that is characteristic of many inhalation anesthetics was recorded in only a few instances. Also absent were the burst-suppression patterns or EEG fast waves typical of barbiturates and other sedative-hypnotics.

Effects on visually evoked responses. The effects of CI-581 on visually evoked responses (VER) were observed in 6 subjects. At doses which produced coma, depression of the primary complex of the VER and enhancement of a portion of the secondary complex were observed, as pre- 

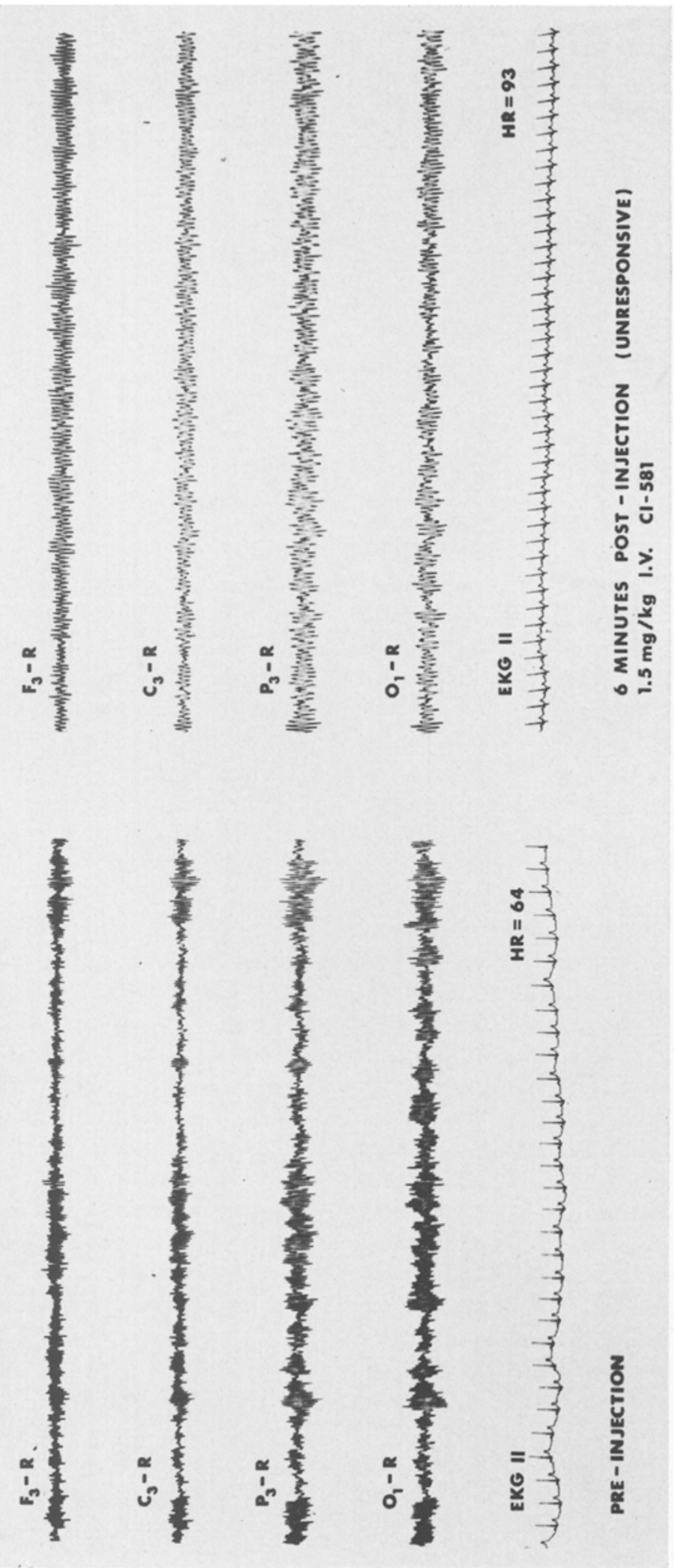


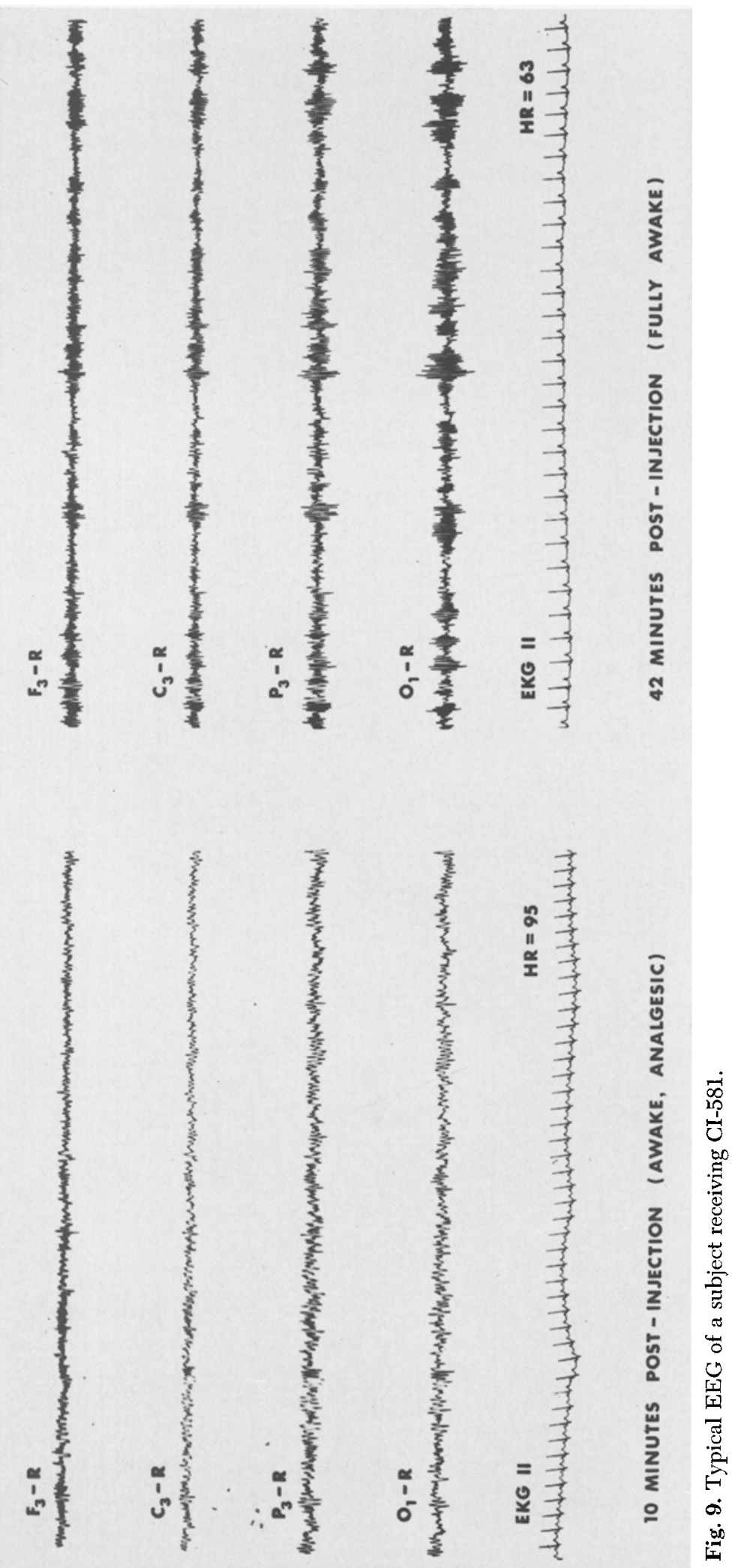


viously reported with other substances which promote sleep or loss of consciousness. ${ }^{2}{ }_{4}^{4}$ In addition, the rhythmic afterdischarge following the light flash was abolished. These observations were in keeping with the disappearance of alpha rhythm from the EEG patterns. Fig. 10 illustrates the VER changes in one subject. During the saline infusion a typical response was obtained by light directed into the subject's eyes at a flash rate of 1 per second. The arrows in Fig. 10 indicate the light stimulus which is followed by the summated VER for $500 \mathrm{msec}$. With the subject's eyes closed, a reproducible series of electrical waves can be recorded. This is followed by a rhythmic afterdischarge with a frequency similar to alpha rhythm. CI-581 in a dose of $2.0 \mathrm{mg}$. per kilogram altered the VER as illustrated. The evoked potentials gradually returned toward control levels after the patient recovered from coma.

Effects on somesthetic responses. The effect on somesthetic input was of particular interest in view of this drug's ability, in the awakening patient, to produce subjective numbness without blocking touch sensation. The summated cerebral somesthetic responses were determined by stimulation of the contralateral medial nerve. Somesthetic responses elicited at three times the sensory threshold were recorded before the injection, at the height of coma, and during recovery. For recording the short latency component, an analysis time of $125 \mathrm{msec}$. was used; for long latency components, 500 msec. At doses ranging from 0.5 to $2.0 \mathrm{mg}$. per kilogram, enhancement of the initial components of the somesthetic response was recorded which persisted throughout coma (Fig. 11). It is noteworthy that at the time the subject complained of numbness and yet could feel stimuli to the contralateral wrist, the evoked response was obtained from the "hand area" in the brain. Although the short latency responses were clearly present, the much longer latency responses beyond $90 \mathrm{msec}$. were reduced. Usually these responses did not return to control levels until $1 / 2$ to 2 hours after drug administration.

Laboratory studies. The effects of CI-581 on liver and kidney function, electrolytes, and blood counts were determined the day before drug injection and also 3 and 7 days
ORUG TREATMENT $0.9 \%$ SALINE

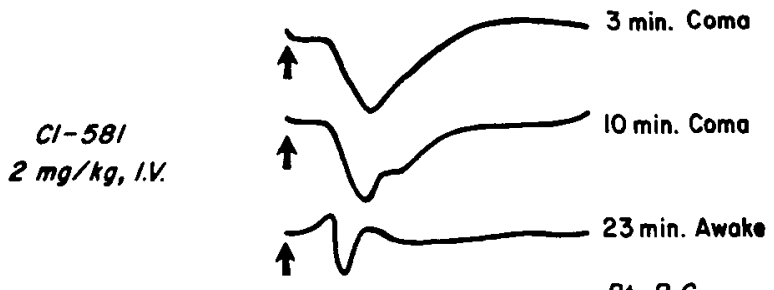

Pf. R.C.

Fig. 10. Effects of CI-581 on visually evoked response. 

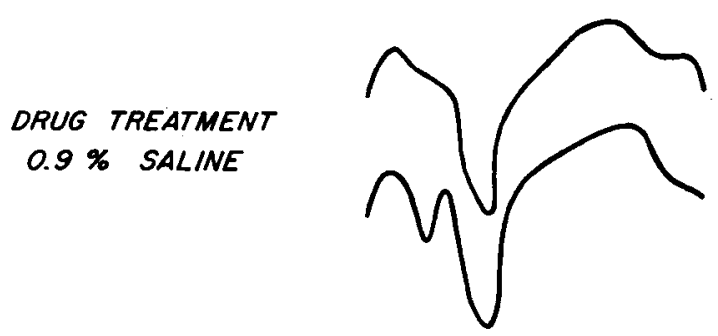

$0.9 \%$ SALINE
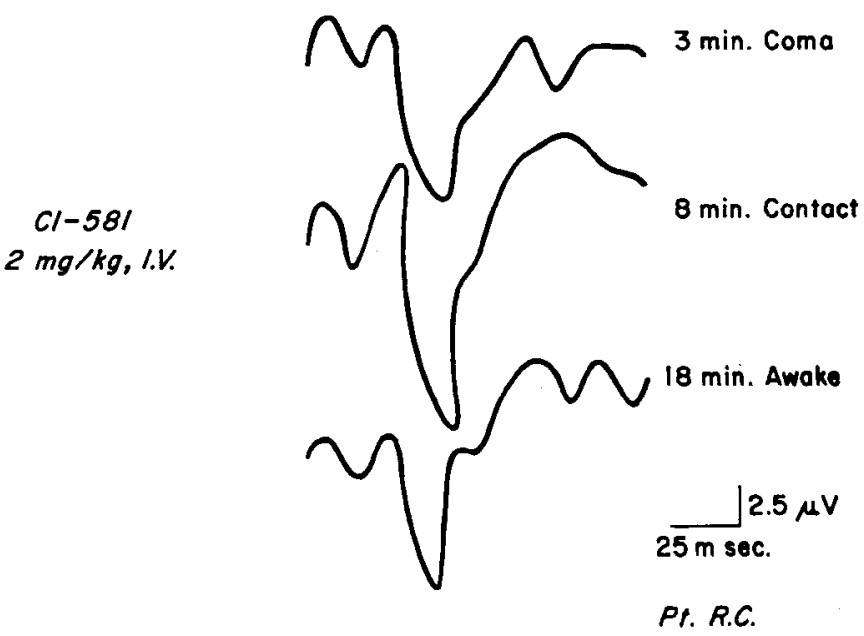

Fig. 11. Effects of CI-581 on somesthetically cvoked responsc.

afterward. As indicated in Table I, these values were not significantly affected by the drug.

\section{Discussion}

The studies demonstrate that CI-581 exerts pharmacologic actions in man which are similar to those reported for laboratory animals. ${ }^{7}$ CI-581 is less potent and shorter acting than the parent drug, phencyclidine, but otherwise quite similar. At equivalent analgesic dosages, CI-581 is about onefourth as potent as phencyclidine; however, in degree of analgesia and coma, the two drugs are about equal, so that CI-581 appears to be as effective as phencyclidine in the induction of analgesia and anesthesia.

No convulsions were noted in our subjects, with a fourfold increase in dosage of CI-581. This finding seems to be in contrast with that reported for phencyclidine. Also the shorter duration of action of CI-581 should be a distinct advantage in cases where brief analgesia and anesthesia are required. Minute-to-minute control may be achieved by additional doses or by an infusion technique.

The principal disadvantage of phencyclidine is its adverse psychic effects. In our studies CI-581 produced very similar qualitative alterations; quantitatively, however, these reactions were considerably shorter in duration than those reported for phencyclidine. Some of the changes apparently represent a primary pharmacologic action of this class of compounds. Most of the subjects showed changes in mood, body image, and affect, and some reported vivid dreams and/or hallucinations. In some cases the subjects found the experience frightening and described it as like death or like being in outer space. It is of considerable importance, however, that the psychic alterations induced by CI-581 were short lasting, 
and that some of the subjects experienced no undesirable effects at all.

Whether the incidence of pathologic mental changes may limit the clinical usefulness of CI-581 needs to be evaluated further. It should be emphasized that the volunteers purposely received no preanesthetic medication. The possible effects of premedicants on the psychic state, as well as coma, analgesia, and blood pressure, are yet to be clarified. The basic pharmacologic experiments obviously must be supplemented by studies of the drug under actual clinical conditions. Such studies are now in progress.

One of the most remarkable features of CI-581 is its ability to produce profound analgesia. With this drug as the sole analgesic and anesthetic agent, it is possible to carry out painful operative procedures of short duration (Corssen and Domino, to be published). In coma-producing doses, CI-581 causes transient dose-related respiratory depression that is not clinicaly significant.

The cardiovascular actions of CI-581 follow a predictable pattern. The drug consistently produces an increase in systolic and diastolic blood pressure as well as tachycardia. In some subjects the transient hypertension was alarming, while in others it was barely perceptible. These cardiovascular changes, combined with frequent sweating, lacrimation, and hyperactive tendon reflexes, have led Chen and his associates ${ }^{1}$ to suggest that phencyclidine and its derivatives are sympathomimetic. Blood glucose levels tend to rise after CI-581, although not to the degree that might be expected with equal pressor doses of epinephrine. Moreover, the increase in diastolic pressure following CI-581 would rule out epinephrine release as the sole mechanism for the induced hypertension. Increases in blood pressure can take place with doses of CI-581 that do not produce coma; where coma is produced, hypertension usually outlasts the period of anesthesia.

In conclusion, these first human phar- macologic studies of CI-581 indicate that intravenous administration of the drug can produce profound analgesia and short-lasting anesthesia. The powerful analgesic action is of special interest. Respiratory depression is transient and not a serious problem. Many protective reflexes such as laryngeal, pharyngeal, eyelid, and corneal are present during the patient's unresponsiveness. No liver, kidney, or blood abnormalities or venous irritation were noted in the subjects tested. Undesirable pharmacologic effects include marked sympathomimetic activity resulting in hypertension and tachycardia, as well as psychotic changes resembling those seen with phencyclidine ${ }^{3}$ but of much shorter duration. The possible clinical usefulness of CI-581 as a shortacting intravenous anesthetic needs to be studied and probably will depend on whether these undesirable effects can be suppressed by preanesthetic medication.

The unusual analgesic and anesthetic action of this drug with sympathomimetic properties, and cerebral dissociative actions, makes it imperative that a new terminology be developed for drugs of this type. It is suggested that the state produced by this drug be called "dissociative" anesthesia.

We would like to thank Dr. A. Lane and Dr. E. L. Holmes for making available the facilities of the Parke, Davis Clinical Unit at the State Prison of Southern Michigan at Jackson, and Dr. C. E. Moyer of the Clinical Laboratory of Parke, Davis for the laboratory studies.

\section{References}

1. Chen, G., Ensor, C., Russell, D., and Bohner, B.: The pharmacology of 1-(1- phenylcyclohexyl) piperidine $\mathrm{HCl}$, J. Pharmacol. \& Exper. Therap. 127:241-250, 1959.

2. Corssen, G., and Domino, E. F.: Visually evoked responses in man. A method for measuring cerebral effects of preanesthetic medication, Anesthesiology 25:330-341, 1964.

3. Domino, E. F.: Neurobiology of phencyclidine (Sernyl), a drug with an unusual spectrum of pharmacological activity, Internat. Rev. Neurobiol. 6:303-347, 1964.

4. Domino, E. F., Corssen, G., and Sweet, R. B.: Effects of various anesthetics on the visually evoked response in man, Anesth. \& Analg. 42: 735-747, 1963. 
5. Domino, E. F., and Corssen, G.: Visually evoked response in anesthetized man with and without induced skeletal muscle paralysis, Ann. New York Acad. Sc. 112:226-237, 1964.

6. Jasper, H. H.: The ten twenty electrode system of the International Federation, Electroencephalog. \& Clin. Neurophysiol. 10:371-375, 1958.
7. McCarthy, D. A., and Chen, G. M.: General anesthetic action of 2-(o-chlorophenyl)-2-methylamino cyclohexanone HCl (CI-581) in the Rhesus monkey, Fed. Proc. 24:268, 1965.

8. Snedecor, G. W.: Statistical methods, ed. 5, Ames, Iowa, 1956, Iowa State College Press. 